\title{
Developing International Standards for Very Small Enterprises
}

\author{
Claude Y. Laporte, École de technologie supérieure \\ Simon Alexandre, Centre d'Excellence en Technologies de l'Information et de la \\ Communication
}

\author{
Alain Renault, Henri Tudor Public Research Center-Luxembourg
}

Software engineering standards must address the needs of small organizations, especially those with a low capability level.

Industry recognizes that very small enterprises (VSEs) contribute valuable products and services. In Europe, for example, 85 percent of the information technology (IT) sector's companies have only one to 10 employees. According to a recent survey, 78 percent of software development enterprises in the Montreal area have fewer than 25 employees, while 50 percent have fewer than 10. The Organization for Economic Cooperation and Development (OECD) reported that enterprises with fewer than 10 employees represent 93 percent of all companies in Europe and 56 percent in the US-66 percent of total employment.

Studies and surveys confirm that current software engineering standards do not address the needs of these organizations, especially those with a low capability level. Compliance with standards such as those from ISO and the IEEE is difficult if not impossible for them to achieve. Subsequently, VSEs have no or very limited ways to be recognized as enterprises that produce quality software systems in their domain. Therefore, they are often cut off from some economic activities.

Research shows that VSEs find it difficult to relate ISO standards to their business needs and to justify the application of the standards to their business practices. Most of these VSEs can't afford the resources-in number of employees, cost, and time-or see a net benefit in establishing software life cycle processes.

\section{HISTORY}

To rectify some of these difficulties, delegates from five national bodies of the 2004 SC7 plenary meeting in Australia reached a consensus regarding the necessity of providing VSEs with standards adapted to their size and particular context, including a set of profiles and guides. They agreed on the following general objectives:

- make the current software engineering standards more accessible to VSEs;

- provide documentation requiring minimal tailoring and adaptation effort;

- provide harmonized documentation integrating available standards such as process standards, work products and deliverables, assessment and quality, and modeling and tools; and

- take into account, if desirable, the notions of capability and maturity levels presented in ISO/IEC 15504 and CMMI.

In 2005 at the SC7 Plenary meeting in Finland, Thailand proposed the creation of a new working group to meet these objectives. Twelve countries voted in favor of establishing such a group, named Working Group 24 (WG24): Belgium, Canada, the Czech Republic, Ireland, Italy, Japan, Korea, Luxemburg, South Africa, Thailand, the UK and the USA The group appointed Thailand's Tanin Uthayanaka as convener. It also appointed Claude Y. Laporte, representing the IEEE Computer Society, as project editor, and Jean Bérubé, a delegate from Canada, as secretary.

\section{VSE SURVEY PRESENTATION}

To refine the VSE requirements, WG24 decided to conduct a survey to question VSEs about their utilization of ISO/SC7 standards. They also wanted to collect data to identify problems and potential solutions that would help them apply standards and become more competitive. This survey's responses appear in Table 1.

(C) 2008 IEEE. Personal use of this material is permitted. Permission from IEEE must be obtained for all other uses, in any current or future media, including reprinting/republishing this material for advertising or promotional purposes, creating new collective works, for resale or redistribution to servers or lists, or reuse of any copyrighted component of this work in other works. The final publication is available at http://dx.doi.org/10.1109/MC.2008.86 
Table 1. Number of very small enterprise (VSE) survey responses per country.

\begin{tabular}{|l|r|l|r|}
\hline Country & Number of responses & Country & Number of responses \\
\hline Argentina & 2 & Italy & 2 \\
\hline Australia & 8 & Japan & 3 \\
\hline Belgium & 10 & South Korea & 4 \\
\hline Brazil & 68 & Mexico & 20 \\
\hline Bulgaria & 3 & New Zealand & 1 \\
\hline Canada & 8 & Peru & 4 \\
\hline Chile & 1 & Russia & 4 \\
\hline Colombia & 88 & South Africa & 10 \\
\hline Czech Republic & 3 & Spain & 2 \\
\hline Ecuador & 9 & Taiwan & 1 \\
\hline Finland & 13 & Thailand & 52 \\
\hline France & 3 & Turkey & 1 \\
\hline India & 57 & United Kingdom & 2 \\
\hline Ireland & 10 & United States & 3 \\
\hline
\end{tabular}

From the beginning, WG24 drew up several working hypotheses regarding VSEs. The survey was intended to validate some of these hypotheses, including the following:

- The VSE context requires light and well-focused life-cycle profiles.

- Particular business contexts require particular profiles.

- There are significant differences in terms of available resources and infrastructure between a VSE employing 1 to 10 people and an IT department of the same size in a larger company.

- VSEs are limited in both time and resources, which leads to a lack of understanding about how they can use standards for their benefit.

- Benefits for VSEs might include recognition through assessment or audit by an accredited body.

WG24 developed and translated into nine languages a Web-based survey questionnaire to obtain responses from the following countries: England, France, Germany, Korea, Portugal, Thailand, Turkey, Russia, and Spain. The 392 respondents included 228 enterprises (58 percent) with 0 to 25 employees.

Since the survey was initiated through WG24 contacts without building a true random sample, the survey results might have been affected. The geographical distribution of answers provided the first observation about the respondent sample: Many responses were from Latin America (46 percent), mainly from Colombia (22 percent) and Brazil (17 percent).

At the same time, there were only a few responses from European countries, Japan, and the US. This might be either because the invitation to participate in the survey was not relayed to VSEs in some countries, or that most VSEs do not care about IT standardization, so only those aware of it or interested in this subject took the time to contribute.

More than 70 percent of VSEs that responded to the study are working on life- or mission-critical systems (40 percent) or in a regulated market (34 percent). This underscores our hypothesis concerning the awareness of the participating companies, as we assume that companies working in these particular contexts are prone to using standards for contractual reasons.

Among the respondents, 79 percent are private companies and 78 percent operate at the national level only. When requested to select their application domains, VSEs indicated that almost half are working either on life- or mission-critical systems or on regulated projects. With regard to the types of software development, most are involved in customized software and specialized products.

\section{STANDARDS USE}

The survey found a marked difference in the percentage of certified companies with regard to company size: less than 18 percent of VSEs are certified, while 53 percent of larger companies (those with more than 25 employees) claim to be certified. Further, among the 82 percent of VSE not certified only 25 percent claim to use standards. In larger companies using standards, two families of standards and models emerge from the list: ISO standards (55 percent) and models from the Software Engineering Institute (47 percent).

WG24 anticipated the weak use of standards by VSEs by asking questions designed to provide a better understanding of the reasons for this. Three reasons predominated: first, a lack of resources (28 percent); second, that standards are not required (24 percent); and third, the nature of standards themselves-15 percent of the respondents consider that the standards are difficult and bureaucratic and do not provide adequate guidance for use in a small business environment.

A three-quarters majority of VSEs feel it is important to be evaluated or certified against a standard- 40 percent of them request ISO certification. Of the 28 percent requesting official market recognition, only 4 percent are interested in a 
national certification. From the VSE perspective, the benefits that certification provides include increased competitiveness, greater customer confidence and satisfaction, greater software product quality, increased sponsorship for process improvement, decreased development risk, facilitation of marketing, and higher potential to export.

However, VSEs also express the need for assistance to adopt and implement standards. More than 62 percent would like more guidance with examples, and 55 percent asked for lightweight and easy-to-understand standards, complete with templates. Finally, the respondents indicated that it must be possible to implement standards with minimum cost, time, and resources.

\section{THE WG 24 APPROACH}

WG24 used the concept of ISO profiles (ISP: International Standardized Profile) to develop the new standard for VSEs. A profile is defined as "A set of one or more base standards and/or ISPs, and, where applicable, the identification of chosen classes, conforming subsets, options and parameters of those base standards, or ISPs necessary to accomplish a particular function." From a practical point of view, a profile is a kind of bill of material composed of parts of standards such as ISO/IEC 12207 or ISO/IEC 15504. .

To develop this new standard for VSE, WG24 followed an overall approach consisting of three steps:

- target low-capability VSEs,

- select the ISO/IEC12207 process subset applicable to VSEs of less than 10 employees,

- tailor the subset to fit VSE needs, and

- develop guidelines.

WG24 began by looking for existing standards or models that could be tailored to suit VMEs. At the 2006 SC7 Plenary meeting in Thailand two new countries, India and Mexico, sent delegates to WG24. At that meeting, the group selected Moprosoft, a Mexican standard developed to assist Mexican small and medium enterprises (SMEs), to achieve this objective. Moprosoft uses ISO/IEC 12207 as a general framework. It borrows practices mainly from IS09001, the Capability Maturity Model Integration (CMMI), and the Project Management Body of Knowledge (PMBOK).

However, WG24 felt that Moprosoft addresses the needs of organizations larger than targeted VSEs. Therefore, as a second step, WG24 decided to tailor Moprosoft to address key characteristics of low-capability VSEs. As a starting point, the tailoring approach led to the development of incremental profile targeting of low-capability VSEs of fewer than 10 employees and, in a second phase, those with 10 to 25 employees. The first profile contains basic tasks coming from project-management and software-development-related processes. The idea was to concentrate on core activities that a low-capability VSE should perform.

The approach's third step consisted of defining guidelines explaining in more detail the processes defined in the profile. These guidelines will be published as ISO technical reports and should be freely accessible to VSEs. The guidelines integrate a series of deployment packages that provide a set of artifacts developed to facilitate and accelerate the implementation of a set of practices for the selected framework in a VSE.

The elements of a typical deployment package include a process description (tasks, inputs, outputs, and roles), guide, template, checklist, example, presentation material, mapping to standards and models, and list of tools to help VSEs implement the process. As Figure 1 shows, WG24 designed the deployment packages so that a VSE can implement its content without having to implement the complete framework at the same time. 


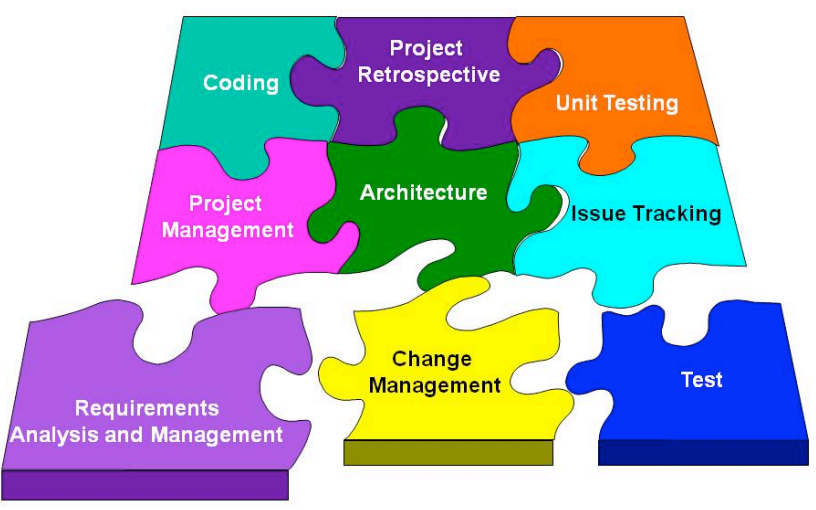

Figure 1. Example of deployment packages.

Such packages are designed so that a very small enterprise can implement its content without having to implement the complete framework.

\section{RECENT DEVELOPMENTS}

At the WG24's October 2007 meeting in Canada, a new country, Colombia, and a new institution, the European Software Institute, joined the WG24. The group members reviewed and offered broad support to a requirement analysis and management deployment package. The group decided to develop three deployment packages for its May 2008 meeting in Berlin: change management, project management, and testing.

Having profiles and guides for VSEs is insufficient to ensure broad utilization and adoption: They must be tested with VSEs from at least a few countries. The Mexican delegation introduced, as pilot projects, the first profile developed by WG24 for distribution in Latin American countries. Drafts of a first set of ISP and technical reports have been circulated for comment within SC7, with WG24 scheduled to review them at the 2008 SC7 Plenary meeting in Germany.

WG24 plans to invite a few VSEs that responded to the survey to participate in field trials that will be held to pilot the proposed profiles. Since a few WG24 delegates are already working closely with VSEs, they will play a key role in the trials' coordination. These trials will help validate the approach and provide feedback to improve the documents before going for ISO/IEC publication.

WG24 plans to produce a final draft in 2009, with publication by ISO/IEC scheduled for 2010. In the meantime, the group will make deployment packages freely available to VSEs. The group also will develop other profiles, covering different capability levels and application domains, such as finance or defense. More information and-eventually, deployment packages_can be found at http://profs.logti.etsmtl.ca/claporte/English/VSE/index.html and www.cetic.be/indexEN.php3

Claude Y. Laporte is a software engineering professor at the École de technologie supérieure (ÉTS) Québec (Canada). Contact him at Claude.Y.Laporte@etsmtl.ca

Simon Alexandre is in charge of the Software and System Engineering R\&D Department at CETIC, an ICT research center in Belgium. Contact him at simon.alexandre@cetic.be

Alain Renault is a project leader at the Henri Tudor Public Research Center-Luxembourg. Contact him at alain.renault@tudor.lu

Keywords: standards, software engineering standards, lifecycles, very small enterprises, ISO 